\title{
Letramento e polifonia: um estudo de aspectos discursivos do processo de alfabetização
}

\author{
Cecília M. A. Goulart
}

Universidade Federal Fluminense, Faculdade de Educação
Foi aí que nasci. Nasci na sala do $3^{\circ}$ ano, sendo professora D. Emerenciana Barbosa, que Deus tenha. Até então, era analfabeto e despretensioso. Lembro-me: nesse dia de julho, o sol que descia da serra era bravo e parado. A aula era de Geografia, e a professora traçava no quadro-negro nomes de países distantes. As cidades vinham surgindo na ponte dos nomes, e Paris era uma torre ao lado de uma ponte e de um rio, a Inglaterra não se enxergava bem no nevoeiro, um esquimó, um condor surgiam misteriosamente, trazendo países inteiros. Então, nasci. De repente nasci, isto é, senti vontade de escrever. Nunca pensara no que podia sair do papel e do lápis, a não ser bonecos sem pescoço, com cinco riscos representando as mãos. Nesse momento, porém, minha mão avançou para a carteira à procura de um objeto, achou-o, apertou-o irresistivelmente, escreveu alguma coisa parecida com a narração de uma viagem de Turmalinas ao Pólo Norte.

C. D. de Andrade. Contos de Aprendiz. Rio de Janeiro: Livraria José Olympio Editora, 1975, p. 153-154.

Um desafio que se coloca hoje para a escola é como trabalhar a apropriação e a criação de conheci- mentos, com base na relação passado/presente/futuro, de modo a não perder o sentido histórico dos sujeitos e da sociedade, estando inseridos todos, professores e alunos, numa dinâmica social altamente complexa e heterogênea, de uma sociedade capitalista que apela precipuamente para aspectos individuais dos sujeitos e para o aqui e o agora.

A dinâmica social mostra-se complexa e heterogênea, com múltiplas perspectivas. Destaco aqui, principalmente, a perspectiva cultural, que se expressa em diferentes áreas do conhecimento (filosófica, científica, lingüística, artística, de gênero, étnica, religiosa, entre outras), e a perspectiva de classes sociais, que se expressa pelos diferentes valores atribuídos por estas classes aos diferentes conhecimentos, agências, objetos, atividades, relações e atitudes sociais. As formas como hoje esses conhecimentos se cruzam, aproximando-se e afastando-se, ao mesmo tempo, geram necessidades cada vez mais urgentes de se continuar repensando, entre muitas outras questões, e, no sentido deste estudo, a prática pedagógica discursiva, no interior da prática social, nas suas múltiplas dimensões.

A discussão sobre o papel da escola, que já teve 
como orientação dominante a transmissão unidirecional de conhecimentos pelo professor, para a sua ampliação pelos alunos, vem sendo encaminhada no sentido de, além de ampliar os conhecimentos, ampliar as possibilidades de todos nela envolvidos continuarem ampliando os conhecimentos fora dela. O movimento interativo da sala de aula vem-se destacando como um fator importante na construção de conhecimentos e, mais, na possibilidade de se investigar como os conhecimentos que o aluno traz para a escola dialogam e se ampliam com os conhecimentos que a escola coloca em circulação (embora investigações com enfoques diferentes, podemos citar Smolka, 1991; Mortimer e Machado, 1997; Machado, 1999; Azevedo, 2000). Estes estudos vão adensando a compreensão da importância do papel da linguagem verbal no processo pedagógico, bem como fortalecendo a concepção da linguagem como atividade constitutiva, que se faz e refaz pelo sujeito na direção do Outro, isto é, na perspectiva ética da alteridade. É com base nessa realidade pressuposicional que este estudo procura avançar.

Os estudos de Bakhtin, de modos diversos, fundamentam os trabalhos acima citados, assim como se vêm mostrando produtivos para a minha pesquisa, que tem como foco a prática alfabetizadora e os processos de apropriação, pelas crianças, da linguagem escrita. Nesse sentido, em textos anteriores (Goulart, 1999, 2000a, 2000 b), venho cada vez mais me aproximando da noção de letramento, como também buscando compreender-lhe os limites e as possibilidades. Esta aproximação e esta busca me encaminham a alguns aspectos da teoria bakhtiniana, que estarei aqui discutindo, entremeada com estudos de outros autores.

O presente estudo caracteriza-se pela constituição de uma base teórica inicial que aprofunde a compreensão de aspectos da noção de letramento na perspectiva de ampliar possibilidades de discutir novas bases para a prática alfabetizadora. Neste sentido são apresentados indícios da entrada de outras vozes em textos escritos de crianças de seis anos, trabalhados na pesquisa de 1997 (Pacheco, 1997). O objetivo geral é dar continuidade à discussão e explicitação de uma concepção teórico-metodológica de alfabetização que parece se organizar na direção do que é definido como letramento.

O trabalho alfabetizador aqui ressaltado vem sendo desenvolvido no Colégio Fernando Rodrigues da Silveira-Colégio de Aplicação da UERJ (CAp-UERJ) e tem como ponto de partida os textos orais produzidos pelas crianças e professores em diálogo, bem como os textos escritos que circulam na sala de aula de várias maneiras e com várias funções. Um primeiro levantamento dos pressupostos teórico-metodológicos que fundamentam essa prática pedagógica está em Goulart (2000a) e foi realizado principalmente com base nas ações e propostas da professora. Em Goulart (2000c), analiso dados que evidenciam o sujeito da/na linguagem, por meio da análise de reelaborações na perspectiva sintático-discursiva que as crianças realizam no processo de aprender a escrever produzindo textos. A escolha dessa escola pública como locus de pesquisa deveu-se à prática alfabetizadora inovadora que ali vem sendo estudada, discutida e desenvolvida por alguns professores desde o final da década de 1990. Venho observando que, ao analisar um modo de aprender, ressalta-se um modo de ensinar. A pesquisa que realizo desde o final de 1998, e da qual o presente estudo faz parte, vem procurando compreender aspectos desse modo de ensinar/aprender.

Os textos dos alunos são, neste momento da investigação, observados na dimensão alteritária do processo de constituição da linguagem verbal, neste caso, a modalidade escrita. Nesta concepção, o Outro é condição para a constituição do discurso. Relaciona-se deste modo a noção de polifonia com a noção de letramento, como veremos adiante. É na intersubjetividade que os sujeitos e os sentidos se constituem.

No estudo, de base fundamentalmente bakhtiniana, a interlocução assume um estatuto teórico específico; a proposta pedagógica trabalhada pela professora das crianças, cujos textos são objetos de nossa pesquisa, tem no diálogo a condição básica para o desenvolvimento de suas aulas; esta explicitação torna possível pensar em depreender dos textos dos alunos marcas dos discursos alheios, constituindo a sua linguagem. Os indícios são considerados dados privilegiados que 
marcam os textos na perspectiva de significar sinais, "pegadas", do fenômeno que está sendo investigado (cf. Ginzburg, 1989). A análise e as hipóteses explicativas que se vão elaborando no processo de investigação vão consubstanciando conclusões que podem tanto enriquecer propostas pedagógicas de alfabetização, quanto iluminar outras pesquisas.

\section{Letramento como campo de pesquisa}

Estudos sobre a noção de letramento e sobre o que é ser letrado numa sociedade letrada vêm merecendo a atenção de alguns pesquisadores (Soares, 1998; Kleiman, 1995; Tfouni, 1996). Em termos gerais, o letramento está relacionado ao conjunto de práticas sociais orais e escritas de uma sociedade e, também, segundo Tfouni, à construção da autoria.

O termo letramento vem sendo considerado necessário, uma vez que se observa o termo alfabetização muito relacionado a uma visão da aprendizagem da língua escrita como um processo de codificação de sons em letras, para escrever, e o movimento oposto, de decodificação, para ler. Esta visão está, de um modo geral, ligada à suposição de que a linguagem escrita é a fala por escrito. Ou, de um outro modo, supõe que os sistemas escritos teriam sido inventados para representar a fala. Os autores que defendem esta idéia entendem também que "a história da escrita seja a evolução progressiva que culmina no alfabeto" (Olson, 1998, p. 93). Esta tem sido considerada, entretanto, uma visão etnocêntrica dessa história (Michalowski, 1994). A questão tem gerado debates bastante interessantes que podem enriquecer nossos conhecimentos em três perspectivas: da elaboração da história da própria escrita; do ensino/aprendizagem da leitura e da escrita; e também de como a aprendizagem da escrita afeta a cognição. Meu interesse, neste momento, localizase na segunda alternativa.

Segundo Michalowski, a escrita não foi primeiramente utilizada como um veículo para a preservação da tradição oral. O autor afirma justamente o contrário: a escrita foi uma nova forma de comunicação que trouxe à tona uma nova semiótica e novas formas de discurso (p.60). Olson, por sua vez, defende que a escrita não seja uma transcrição do discurso oral, mas que possibilita a elaboração de um modelo conceitual para o discurso, por nos permitir detectar não só os elementos lingüísticos, mas também as estruturas lingüísticas em que estes elementos se inserem.

O denso estudo de Morrison (1995) discute basicamente a tese do aculturamento grego, na qual Orson (1977) postula que a invenção do alfabeto grego, no século VIII a. C, gerou o texto escrito e estabeleceu a sua prioridade sobre a oralidade. Morrison contrapõe-se a essa idéia, postulando, por meio de muitas evidências, que foram as mudanças históricas, ocorridas no desenvolvimento da estrutura textual, que ampliaram sua organização racional, o que o faz distinguir língua escrita de textualidade, bem como sistema lingüístico de sistema textual. Morrison parece caminhar na direção de Michalowski ao centrar sua atenção na linguagem escrita, como uma nova forma de conhecer, e não na língua escrita, como uma nova tecnologia.

De acordo com o ensaio, o texto só começou a existir quando a página (e não a frase ou a declaração, como conceitos lingüísticos) passou a ser a unidade predominante de sua organização. Inovações medievais na apresentação do texto redefiniram a disposição espacial do escrito, alterando os princípios textuais e originando procedimentos mais claros. Morrison argumenta que o sentido é tão inerente aos modelos de organização textual quanto às estruturas lingüísticas. $O$ autor critica "uma teoria do aculturamento que identifique o desenvolvimento cultural em função de apenas um termo de uma separação dicotômica entre o oral e o escrito, o pertencente e o não-pertencente à cultura escrita, ou o mítico e o racional" (p.166-167).

Morrison analisa pesquisas que o levam a relacionar o começo da utilização intensa, nos textos escritos, das notas de rodapé e da citação, à mudança no conceito de fato histórico, já que os julgamentos conclusivos do narrador oral foram substituídos por fontes e referências comprováveis contidas no próprio texto. No método textual de discurso, o conceito do que é real em história começa a depender cada vez mais da 
competência dos textos de corroborarem as afirmações por meio de um aparato acadêmico explícito, isto é, o fato e o texto se aproximam, no sentido de que "os homens começam a pensar os fatos não como registrados pelos textos, mas como incorporados neles" (Stock apud Morrison, 1995, p.169).

O tipo de texto que orienta a discussão de Morrison é o acadêmico, que foi se desenvolvendo historicamente junto com o aprimoramento técnico do trabalho científico. O autor aponta dois aspectos explícitos da língua escrita que transformam a obra (que pode ser oral ou escrita) em texto (escrito): as mudanças específicas que ocorrem no nível do uso gramatical e a organização estrutural. Este segundo aspecto está relacionado ao layout expositivo do livro e da página, ao surgimento de um sistema de exegese e de um sistema de pontuação, que dão sentido e clareza à ordenação das frases, e uma divisão inteligível do texto/conhecimento para a organização das idéias "que expressam pontos de ênfase conceitual" (1995, p.171). Nas palavras do autor,

O texto deve incluir um aparato que imponha uma estrutura formal a uma linha de raciocínio que faz referência explícita ao contexto criado pelo ato de se esquematizar uma obra escrita extensa. [...] cuja distribuição foi estabelecida conforme as unidades do texto, tais como a página, o parágrafo e o capítulo". (idem, p. 172)

O autor postula, então, que "a associação entre o conhecimento e a organização textual é indispensável para a capacidade de uma cultura quanto à ordenação e codificação do conhecimento" (idem, p.191). As mudanças históricas na estrutura textual geraram um conjunto de práticas, formando um conhecimento social relacionado às argumentações históricas e filosóficas, bem como às necessidades de outros ramos particulares do conhecimento. Essas organizações discursivas parecem-nos estar relacionadas ao que Bakhtin (1992) denominou de gêneros do discurso secundários. Segundo o autor, os gêneros do discurso são tipos de enunciados que vão se padronizando pelo uso repetido, em função de conhecimentos específicos de esferas sociais da realidade. Os gêneros secundários estão fortemente vinculados à língua escrita, diferentemente dos gêneros primários.

A pesquisa de Mello (1998) tem relevância político-ideológica para o exame dos estudos acima. Convergindo em parte para o estudo de Morrison, discute como historicamente se trabalhou para fazer crer que uma certa racionalidade, tornada absoluta e universal, e estreitamente associada à escrita, era/é a verdade. Este centramento em uma verdade/ racionalidade vem excluindo parcelas enormes de seres humanos "que não compartilham das referências culturais letradas ocidentais" (p. 3). Mello aponta que os sujeitos organizam o real e elaboram suas concepções e critérios racionais de forma intimamente relacionada com suas vivências, práticas e relações pela/na cultura, engendrando múltiplas formas de ser racional. A lógica formal refere-se, então, a uma forma de ser, social e historicamente constituída, e eleita como universal pela cultura ocidental. De acordo com a autora, os critérios desta lógica controlariam, selecionariam e distribuiriam a produção dos lugares do que é considerado legítimo socialmente; com esses critérios, de um modo geral, mede-se a racionalidade humana. Do ponto de vista bakhtiniano, podemos dizer que a lógica, vista como um signo ideológico (variável e flexível), assume um caráter monovalente, "abafando ou ocultando a luta de índices de valor que aí se trava" (Bakhtin, 1988, p. 46), isto é, abafa ou oculta outras possibilidades de pensar logicamente.

A mesma autora destaca a importância de estudos que cheguem à "revelação pequena, constante e indiciária dos procedimentos engendrados que excluem, da ordem do legítimo, da verdade que há séculos vem sendo globalizada, seres humanos e culturas diversas" (p. 5). Destaca também a necessidade de buscar compreender mais especificamente as formas de organização do real dos sujeitos adultos não alfabetizados de modo a entender outros universos racionais.

Entendemos o entrecruzamento do estudo de Mello, de Morrison, bem como de Michalowski, à medida que podemos reconhecer o que Street (1984) propõe, ao conceber o modelo ideológico de letramento em oposição ao modelo autônomo de letramento. No 
modelo ideológico, o autor ressalta a dimensão político-ideológica daquela noção. Segundo Soares (1998, p. 75),

Street afirma que a verdadeira natureza do letramento são as formas que as práticas de leitura e escrita concretamente assumem em determinados contextos sociais, e isso depende fundamentalmente das instituições sociais que propõem e exigem essas práticas.

Soares apresenta outras questões polêmicas em relação à noção de letramento. Destaco aqui apenas algumas que me parecem mais problemáticas no sentido estrito da palavra. Primeiramente, a dificuldade de conceituar letramento; em segundo lugar, a possibilidade de se conceberem letramentos, no plural; e em terceiro, como consequiência das duas questões anteriores, a falta de condição para definir critérios para avaliar ou estabelecer diferentes níveis de letramento. Estamos portanto trabalhando em terreno movediço, mas que, por isso mesmo, necessita de estudos para ganhar consistência.

A perspectiva acima delineada interliga a noção de letramento a um modo de conceber a linguagem escrita e seu contexto socioistórico, problematizando de modo agudo seu ensino/aprendizagem. Tomando a linguagem verbal como eixo de nosso estudo, tentamos contribuir para o aprofundamento da discussão de aspectos da noção de letramento, que, embora rebelde a definições e contornos, parece-nos bastante promissora. Como pesquisadora ocupada e preocupada com a temática da alfabetização, a minha reflexão vem se centrando no seguinte desafio proposto por Soares: Como alfabetizar, letrando? (Soares, 1988, p. 59)

Rommetveit (1985, p. 183-184) objetiva uma explicação sobre o desenvolvimento da linguagem e do pensamento no sentido de Vygotsky, mas dentro do arcabouço de uma aproximação consistentemente pluralista e social-cognitiva da comunicação humana. Parte da assunção de que o discurso humano acontece num mundo social plural (somente fragmentariamente conhecido) e somente parcialmente compartilhado. Nesta perspectiva, trata a vaguidão, a ambigüidade e a incompletude - mas também a versatilidade, a flexi- bilidade e a negociabilidade - como características inerentes e teoricamente essenciais da linguagem ordinária. Os paradigmas baseados na estipulação de "sentidos literais" invariantes de expressões verbais devem ser abandonados em favor de uma aproximação explicitamente construtivista da linguagem e do pensamento. Os traços sociointeracionais da comunicação verbal, até agora grandemente inexplorados, tais como estados de intersubjetividade e realidade social, bem como padrões de comunicação diádica, devem, segundo o autor, tornar-se o foco de renovadas análises teóricas.

Ao assumirmos um paradigma consistentemente pluralista, abrimo-nos para o repertório de perspectivas humanas possíveis e de inúmeras estratégias de atribuição e categorização inerentes à linguagem ordinária. Assim, segundo Rommetveit (p.186), qualquer "real" estado de coisas é enigmático e permanece assim até que seja visto de uma determinada posição e dentro de alguma perspectiva referencial particular.

Podemos depreender, discutindo e interligando as diretrizes teóricas acima, que, para avançar na direção do estudo sobre letramento, precisamos pensar de modo mais radical na existência de várias racionalidades no espaço social, isto é, de vários modos de ver, ouvir, falar e ler a realidade, de propor perguntas e soluções para aspectos dessa realidade, enfim, de sentir e viver (n)essa realidade. Terzi (1997), com base no estudo de Heath (1982), defende a necessidade de conhecermos as orientações de letramento dos alunos para que possamos compreender seus processos de aprendizagem.

Teale (1992) realizou uma relevante pesquisa sobre as orientações de letramento de 24 crianças americanas pertencentes a famílias de baixa renda, investigando a extensão e a natureza das experiências de letramento das crianças pré-escolares, em suas casas, por meio da análise de diferentes estruturas de participação e domínios de atividades. O autor observa, através das evidências encontradas, que virtualmente todas as crianças numa sociedade letrada têm numerosas experiências com a linguagem escrita antes de entrar na escola. Observa também que essas crianças 
vivenciam o letramento como um processo social. Enfatiza que determinadas atividades de letramento realizadas nos lares se mostram como consequiências inevitáveis da participação e inserção numa sociedade letrada. Destaca que a situação doméstica se constitui num complexo de fatores econômicos, sociais, culturais e pessoais, e que, embora a situação econômica possa afetar as circunstâncias de letramento, isso não é uma regra. $\mathrm{O}$ autor observou instâncias entre as famílias de baixa renda que têm sido caracterizadas por autores como "altamente letradas". Um outro fator a destacar nas ações domésticas de letramento é a alta significação que a interface com instituições sociais diversas revela (escola, trabalho, governo e igrejas, por exemplo).

Estamos aqui entendendo as orientações de letramento como o espectro de conhecimentos desenvolvidos pelos sujeitos nos seus grupos sociais, em relação com outros grupos e com instituições sociais diversas. Este espectro está relacionado à vida cotidiana e a outras esferas da vida social, atravessadas pelas formas como a linguagem escrita as perpassa, de modo implícito ou explícito, de modo mais complexo ou menos complexo. Assumindo com Rommetveit que o mundo social é fragmentariamente conhecido e parcialmente partilhado por cada um de nós, embora coesamente percebido e apropriado, e para nos aproximarmos das orientações de letramento dos sujeitos, é preciso compreendê-lo de forma plural, no sentido das múltiplas perspectivas humanas.

Como a apropriação da linguagem escrita é por nós entendida como parte do processo geral de apropriação da linguagem, a discussão acima vai ao encontro do papel da linguagem na constituição da consciência social dos sujeitos e, logo, da constituição do próprio sujeito como ser social, encontrada nos estudos de Bakhtin (1988). De acordo com o autor, as bases de uma teoria marxista da criação ideológica (estudos sobre o conhecimento científico, a literatura, a religião, a moral) estão ligadas à criação de signos ideológicos, cujos significados remetem a algo exterior aos sujeitos. Os signos não existem como parte de uma realidade: refletem e refratam uma outra, como frag- mentos materiais dessa realidade. Sendo a palavra o fenômeno ideológico por excelência, é absorvida pela sua função de signo e assim penetra em todas as atividades humanas, desde a comunicação ideológica cotidiana, passando pelo discurso interior, até as diversas esferas de saber especializadas e formalizadas. Desse modo, compreender as palavras está relacionado a compreendê-las num contexto concreto preciso, a compreender sua significação numa enunciação particular que se produz dentro de uma esfera social.

De interesse ainda para o nosso estudo é o destaque que Bakhtin dá à ideologia do cotidiano. De acordo com ele, essa ideologia estabelece uma relação dialética com outros sistemas ideológicos constituídos, que estamos concebendo, de um modo genérico, como as disciplinas, os campos do conhecimento: filosofia, ciência, arte, religião, entre outros. Destes sistemas, formados a partir da ideologia do cotidiano, esta ideologia recebe seu tom e, em contrapartida, permite-lhes uma avaliação crítica viva, por meio de uma situação social determinada. Quer dizer, a ideologia do cotidiano garante vida, concretude, significância aos sistemas constituídos. Dessa tensão, ideologia do cotidiano/sistemas ideológicos constituídos/ideologia do cotidiano, é possível aparecerem novas forças sociais que podem invadir a arena da ideologia oficial constituída, infiltrando-se nas instituições ideológicas (a literatura, a imprensa, a ciência). Entendemos então que afastar os campos de conhecimento da realidade cotidiana, portanto, romper esse vínculo, faria com que os campos deixassem de existir, pois deixariam de ser apreendidos como ideologicamente significantes (ver Bakhtin, 1988, p. 118-121). De certo modo, a escola vem trabalhando com as disciplinas, destaque-se aqui a linguagem, dessa maneira: cristalizando-as, ao tornar seus significados monovalentes, sem relação com a vida cotidiana.

Neste sentido, compreender a norma culta da língua, estreitamente associada à língua escrita, parece funcionar para muitos segmentos sociais populares como compreender a palavra estrangeira, analisada por Bakhtin. A idéia está apoiada na perspectiva não só de que a língua portuguesa foi para nós um dia língua 
estrangeira, mas também de que, em geral, a norma culta é trabalhada de modo descontextualizado. Voltando a Bakhtin, nessa parte do trabalho o autor critica os estudos lingüísticos que se voltaram para as línguas mortas estrangeiras, desvinculadas de seu contexto concreto, real (p. 99). Ele afirma que, na consciência histórica dos povos, a palavra estrangeira fundiu-se com a idéia de poder, de força, de santidade, de verdade. Na nossa realidade social, e principalmente escolar, a variedade lingüística tomada como padrão muitas vezes assume esses valores de poder, de força, de santidade, de verdade. Isso se manifesta predominantemente pelo enfoque de caráter formal-sistemático que tradicionalmente conduz o trabalho com a língua, "incompatível com uma abordagem histórica e viva da língua" (Bakhtin, 1988, p. 104).

Pressupomos que seja através do prisma social concreto vivo que nos engloba que lemos o mundo. Mas com que lentes o lemos? Lemos com as lentes da variedade de língua que constituímos interativamente no nosso grupo social, que vive em tensão com as outras variedades usadas, inclusive a padrão, mantendo, de um modo geral, com esta uma relação de submissão. Para Bakhtin, "quanto mais forte, mais bem organizada e diferenciada for a coletividade no interior da qual o indivíduo se orienta, mais distinto e complexo será seu mundo interior" (idem, p. 115). Essa afirmação remete-nos ao nosso estudo de 1999 (Goulart, 1999), quando, ao discutirmos as relações entre escola pública e escola particular, dizemos que é tão alienante uma escola particular (para alunos de classes privilegiadas) que só deixe circular a visão de mundo da classe dominante, quanto uma escola pública (para alunos de classes populares) que só faça circular a visão de mundo da classe dominada, embora saibamos que essa questão na realidade não possa ser vista de modo tão dicotomizado.

Com Bakhtin aprendemos que "o centro organizador de toda enunciação, de toda expressão, não é interior, mas exterior: está situado no meio social que envolve o indivíduo" (p. 121). A noção de polifonia, que entendemos entrelaçada com a de letramento, então, organiza-se a partir desse centro organizador, desse exterior, que é povoado de muitas visões de mundo, muitas palavras, muitas histórias, de várias origens, que dialogicamente se fundam no social. Um social não homogêneo, não transparente: um social ideologicamente opaco, constituído de signos, que é preciso desvendar para "des-cobrir" o mundo (os mundos?).

A noção de polifonia é aqui entendida por meio do fenômeno social da interação verbal como realidade fundamental constitutiva da linguagem e da consciência dos sujeitos. No movimento de interação social os sujeitos constituem os seus discursos por meio das palavras alheias de outros sujeitos (e não da língua, isto é, já ideologizadas), que ganham significação no seu discurso interior e, ao mesmo tempo, geram as contrapalavras, as réplicas ao dizer do outro, que por sua vez vão mobilizar o discurso desse outro, e assim por diante. É então num emaranhado discursivo que se formam o discurso social e os discursos individuais. Como nos acrescenta Bakhtin (1992, p. 313-314):

\footnotetext{
[...] a experiência verbal individual do homem toma forma e evolui sob o efeito da interação contínua e permanente com os enunciados individuais do outro. [...] Nossa fala, isto é, nossos enunciados [...] estão repletos de palavras dos outros, caracterizadas, em graus variáveis, pela alteridade ou pela assimilação, caracterizadas, também em graus variáveis, por um emprego consciente e decalcado. As palavras dos outros introduzem sua própria expressividade, seu tom valorativo, que assimilamos, reestruturamos, modificamos.
}

Segundo o autor, é nesse movimento também que certos sentidos vão se tornando mais estáveis nas diversas situações sociais, marcadas historicamente, e vão se estabilizando gêneros do discurso, tanto ligados às situações da vida cotidiana, quanto às diferentes esferas simples e complexas da vida social. Ainda de acordo com o autor, os gêneros do discurso primários e secundários se inter-relacionam e, de uma forma imediata, sensível e ágil, refletem a menor mudança na vida social.

Os gêneros do discurso são um repertório aberto e heterogêneo de formas de enunciados que foram se organizando, ao longo do tempo histórico, relacionadas a determinados conteúdos e situações sociais. 
Mesmo a seleção de uma palavra, durante a elaboração de um enunciado por um sujeito, passa por outros enunciados ouvidos/lidos que, na maioria das vezes, são aparentados à especificidade do gênero que está sendo utilizado (p. 311). Esses enunciados/gêneros parecem formar-se polifonicamente, porque estão ligados, não só aos elos que os precedem, mas também aos elos que os sucedem, na cadeia de comunicação verbal: o papel dos outros, como interlocutores, destinatários - participantes ativos, é, então, fundamental.

Bakhtin atribui grande importância teórica à distinção entre os dois tipos de gênero, salientando que não se deve trivializar os gêneros primários, colocando-os como ponto de referência, e que se deve levar em conta a inter-relação de gêneros primários e secundários, bem como o processo histórico de constituição dos gêneros secundários. Situa estes gêneros como ligados à comunicação cultural mais complexa e relativamente mais evoluída, associada à escrita. Embora o autor não discuta a relação entre a língua oral e a língua escrita, diz que, em cada época de seu desenvolvimento, a língua escrita é marcada pelos gêneros do discurso, tanto secundários, quanto primários. Assim como afirma que os gêneros secundários absorvem e transmutam os gêneros primários de todas as espécies, que se constituíram em circunstâncias de uma comunicação verbal espontânea. Nesta transformação os gêneros primários perdem sua relação imediata com a realidade cotidiana e com a realidade dos enunciados alheios, já que esses enunciados passam a se situar como fenômenos de uma determinada esfera social (literária, científica, jurídica) e não como realidade cotidiana, ainda que conservem sua forma e seu significado cotidiano, em alguns casos. O estudo de Morrison apresentado aprofunda a compreensão do processo histórico de constituição de gêneros de discurso secundários, vindo ao encontro do trabalho de Bakhtin. Este autor esclarece mais:

Ignorar a natureza do enunciado e as particularidades de gênero que assinalam a variedade do discurso em qualquer área do estudo lingüístico leva ao formalismo e à abstração, desvirtua a historicidade do estudo, enfraquece o vínculo existente entre a língua e a vida. A língua penetra na vida através dos enunciados concretos que a realizam, e é também através dos enunciados concretos que a vida penetra na língua. (Bakhtin, 1992, p 282)

Quando Bakhtin afirma que "a variedade dos gêneros do discurso pode revelar a variedade dos estratos e dos aspectos da personalidade individual"1 (p. 283), estabelecemos uma ponte entre a noção de polifonia e a noção de letramento, que é central no nosso estudo. Entendemos que a variedade dos gêneros do discurso utilizada por uma pessoa pode revelar a sua variedade de conhecimentos (conhecimentos de vários estratos sociais) e aspectos de sua personalidade, em duas medidas: (i) na medida em que os conhecimentos produzidos pelas diferentes classes sociais circulam na sociedade de um modo geral; e (ii) na medida em que classes sociais diferentes atribuem valores diferentes aos signos ideologicamente constituídos e vivenciam as situações sociais de modos diferentes. $\mathrm{O}$ fenômeno do letramento está então associado a diferentes gêneros discursivos, caracterizando as classes sociais de modo diferente também do ponto de vista discursivo. ${ }^{2}$ Estudos de natureza etnográfica já vêm mostrando desempenhos diferentes de crianças de distintas classes sociais em atividades orais de sala de aula, sem, contudo, estarem apoiados na fundamentação bakhtiniana. Desse ponto de vista, estudos que envolvam a análise das orientações de letramento dos sujeitos podem mostrar-se produtivos, tanto para a compreensão de que saberes circulam na sociedade, e de que modo, quanto para a reflexão sobre processos de aprendizagem.

Como então relacionar polifonia e letramento de modo que contribuam para uma melhor compreensão do

${ }^{1}$ Consideramos que deva ter havido aqui problemas de tradução, conforme foi observado por Castro (1997), analisando uma seção da primeira parte desse mesmo livro. Problemas de tradução vêm sendo observados por outros autores em relação a outras obras de Bakhtin.

${ }^{2}$ A questão da personalidade está associada à discussão que o autor faz sobre a relação entre gênero discursivo e estilo, que, por não se mostrar pertinente ao nosso trabalho nesse momento, não é apresentada. 
processo de alfabetização, no sentido com que nos provoca Soares (1998) de "alfabetizar, letrando"?

Com base na discussão teórica apresentada, a noção de polifonia é entendida, na perspectiva dialética, tanto do que se repete nos discursos e cria, em diferentes grupamentos sociais e de modo relativamente estável, significações e gêneros de discurso, quanto do que se diferencia nos discursos e permite pensar o signo ideologicamente aberto para diferentes interpretações. Como essa noção tem sido relacionada às vozes dos sujeitos, podemos pensar tanto em vozes que se aproximam, consonantes, quanto em vozes que se afastam, dissonantes.

A noção de polifonia é vista como básica para a compreensão da noção de letramento no sentido de que este está relacionado ao conjunto de práticas sociais, orais e escritas, e a instituições, atravessados pelo poder que a língua escrita possui na sociedade e aos conteúdos a que, histórica e culturalmente, essa modalidade de linguagem está associada (Gnerre, 1985). Diante da discussão anterior, estaria, conseqüentemente, relacionado de modo forte à formação dos diferentes campos de conhecimento e das diferentes configurações discursivas. Assim, vivendo em sociedades letradas, tanto os sujeitos escolarizados quanto os não escolarizados são afetados de alguma forma pelo fenômeno do letramento.

Considerando-se essas diretrizes, e entendendose que a apropriação do saber das classes dominantes pelos alunos, ou da leitura que a classe dominante tem da realidade, por si só não garante a mudança nas relações de poder da sociedade (Orlandi, 1988), duas questões mostram-se relevantes na perspectiva do trabalho político-pedagógico de inclusão de grupos sociais tradicionalmente excluídos na dinâmica social: (i) os sujeitos aprenderem o que a escrita faz com eles, assim como o que podem fazer com a escrita; e (ii) a escola trabalhar no sentido de que o conhecimento dos alunos dialogue com o conhecimento (escrito) valorizado socialmente, sem que este se sobreponha àquele.

Na perspectiva pressuposta do conhecimento fragmentário e parcialmente compartilhado que se tem do mundo, a escola pode ser um espaço de abertura para outras vozes e dimensões do conhecimento, para ampliar o mundo social plural dos sujeitos com múltiplos modos de mostrar, apreender, discutir e sentir as faces da realidade. Aumentar-se-ia dessa maneira o espectro fragmentário do conhecimento dos sujeitos. Não de uma forma hierarquizada e homogênea, mas, sob o olhar de Foucault (1996), recusando o discurso "verdadeiro", e discutindo o novo, que não está no que é dito, "mas no acontecimento de sua volta" (p.26). Como o "tema" bakhtiniano que, envolvendo o enunciado, cria-lhe uma significação única, irrepetível. Rompendo o cinturão de poder que se foi formando na sociedade, costurado pela escrita (Rama, 1985), apropriandose do modo como diversos fatos e conhecimentos foram incorporados por ela, e colocando em circulação outros modos de incorporação de fatos e conhecimentos, que podem nos levar a novas formas de tensão social, a novas práticas discursivas, a uma nova ordem do discurso - ou ao diálogo entre as múltiplas formas de ser racional, de acordo com Mello (1998).

Podemos pensar com Bakhtin que o processo acima delineado se ancora na pressuposição de que "Um sentido revela-se em sua profundidade ao encontrar e tocar outro sentido, um sentido alheio; estabelece-se entre eles como que um diálogo que supera o caráter fechado e unívoco, inerente ao sentido e à cultura considerada isoladamente" (Bakhtin, 1992, p. 368). Encaminhando a reflexão sobre a prática pedagógica dessa maneira, entendemos que os alunos formularão novas perguntas às "outras formas de ser racional” que essas formas nem cogitavam. A formulação de novas perguntas permite que as formas "alheias" respondam, assumindo faces novas de sentido. Segundo Bakhtin, somente ao formularmos perguntas próprias (próprias de outras formas de ver o mundo), participamos de uma compreensão ativa de tudo que é outro e alheio.

Aí me parece estar a semente da transformação, unindo o letramento - como a condição de, pela linguagem, ser interno de modo crítico aos conteúdos e formas sociais que, atravessados pela escrita, disputam o jogo do poder no espaço político das relações sociais - e a polifonia - como a compreensão, também crítica, dos outros e alheios - que ao comporem o es- 
pectro discursivo social, compõem o meu discurso, revelando as diferenças/afastamentos entre mim e os outros, as semelhanças/aproximações, bem como as tensões/conflitos.

Como, então, incluir discursivamente o Outro na sala de aula? Que papel o Outro desempenha mais especificamente numa prática alfabetizadora que tem o diálogo como ponto de partida e de chegada? Como o Outro compõe o discurso próprio com o discurso alheio? Como podemos evidenciar esse Outro do discurso constituindo o processo de aprendizagem da linguagem escrita? Na próxima seção apresentamos indícios de vozes de Outros, nos textos infantis.

\section{Letramento e polifonia: evidências do 0 utro no processo de constituição da linguagem escrita}

A sala de aula é, como já foi expresso, de uma escola pública vinculada, como colégio de aplicação, a uma universidade. Embora a variável de classe social não tenha sido considerada, trata-se de uma turma heterogênea, composta por vinte crianças de seis anos, que ali chegaram por terem participado de um sorteio público, além de outras, filhas de funcionários e/ou professores da referida universidade. Todos os professores das séries iniciais do $1^{\circ}$ grau da escola têm o $3^{\circ}$ grau; reúnem-se semanalmente para estudos e discussão de suas propostas de trabalho.

A abordagem dos textos escritos das crianças, aqui realizada, visa subsidiar próximas pesquisas, no sentido de contribuir para a elaboração de uma teoria da alfabetização na perspectiva discursiva do letramento. Na primeira parte da seção, caracterizamos de modo breve o contexto da pesquisa realizada em 1997, que englobou 318 textos escritos por dez crianças durante dois anos, Classe de Alfabetização e $1^{\mathrm{a}}$ série (Goulart, 2000d), apresentando uma releitura de aspectos de seus resultados também de modo sintético. São destacados, em textos elaborados pelas crianças no primeiro semestre da Classe de Alfabetização, indícios da presença de Outro(s), nos processos de constituição da linguagem escrita.

O critério para a seleção das crianças foi que não tivessem descoberto o principio alfabético da escrita. As atividades de escrita propostas pela professora envolvem sempre a produção de textos. Palavras isoladas só são trabalhadas ou no sentido de responder a alguma pergunta de um aluno, em função da escrita dos textos, ou como recurso para destacar alguma dificuldade observada pela professora, ou se valem como texto. O sentido da linguagem escrita é o eixo do trabalho; aspectos gramaticais e ortográficos estão subordinados ao sentido que os textos têm para as crianças e para a professora, sem, contudo, serem negligenciados. De modo dinâmico, considerando as necessidades dos alunos e as observações da professora, aspectos da língua são analisados, tanto para responder a demandas pontuais, quanto de modo sistemático, envolvendo conteúdos linguiísticos específicos dos processos de produção de linguagem oral e escrita.

O diálogo é a condição básica para que o trabalho pedagógico se constitua e para que novos conhecimentos sejam criados. A apropriação da língua escrita pelas crianças é uma meta da professora e dos alunos, mas é focalizada principalmente como linguagem, pela possibilidade de trazer para a sala de aula novos universos discursivos, novas vozes. Desse movimento, as leituras possíveis aos alunos vão se realizando e se adensando, provocando-os no sentido da sua necessidade, e a produção de textos é incentivada. Os textos possíveis também vão sendo realizados e se adensando. Estes textos iniciais permitiram-me caracterizar as estratégias que as crianças utilizam na transição do que chamo de "intenção de texto" " para o texto em que já se podem evidenciar indícios do princípio alfabético do sistema de escrita (Pacheco, 1997; Goulart, 2000d). Permitem-nos, no presente estudo, buscar as marcas da presença do Outro nos processos de constituição da linguagem das crianças, considerando o estatuto teó-

\footnotetext{
${ }^{3}$ A “intenção de texto" se caracteriza pela produção de aglo-
} merados de letras (aparentemente aleatórios) que são lidos pelas crianças de forma significativa e adequada à proposta da professora. Desses aglomerados de letras vão surgindo aos poucos textos legíveis (cf. Pacheco, 1997, p. 5-8). 
rico que o diálogo tem na concepção de linguagem trabalhada.

No período analisado as crianças produziram diferentes tipos de texto: histórias, parlendas, notícias de jornal, anúncios, mensagens, regras de jogo, receitas, letras de música e relatórios de observação. Estes textos foram gerados como consequiência de atividades que envolviam conversas, leituras e discussões, propostas pela turma e pela professora, bem como de necessidades sentidas pelo grupo. Muitos "Outros" entraram, então, na sala de aula, de várias formas e trazendo questões e configurações discursivas de naturezas diferentes para a reflexão das crianças. Pude observar a quantidade e complexidade de conhecimentos que estão envolvidos no processo de alfabetização.

A análise dos textos, em 1997, possibilitou evidenciar, entre as inúmeras estratégias singulares utilizadas pelas crianças para a produção de textos, nove estratégias que chamei de gerais. São elas: (1) o uso de cadeias de letras valendo como partes do texto; (2) o uso de palavras ou expressões legitimadas; (3) o uso de grafemas (sinais de acentuação e pontuação) diferentes de letras; (4) a canonização de sílabas não canônicas; (5) preenchimento aleatório de espaços (isto é, espaços nos quais as crianças consideravam que deveria haver algo escrito); (6) formação de amálgamas de palavras; (7) a utilização do valor sonoro do nome da letra; (8) escrita silábica; e (9) a utilização do pró- prio nome como referência. Não foi observada uma ordem na utilização dessas estratégias pelas crianças. Foi possível indicar com o estudo que o processo de construção do objeto textual escrito é próprio a cada sujeito (ver Goulart, 2000d).

A maioria das estratégias acima mencionada, de alguma forma, evidencia a participação do Outro no processo, considerando que as crianças utilizam os textos escritos legitimados socialmente, com autoria, como fonte para conceberem as suas escritas. O modo de ver o tex to como cadeias de letras; o uso de sinais de pontuação e acentuação de modo aparentemente indiscriminado em textos ainda ilegíveis; a percepção da sílaba padrão da língua (consoante+vogal) e a tentativa de regularização da escrita de palavras com esse padrão; o preenchimento de espaços no texto, configurando o texto de uma dada maneira; todas essas estratégias fundam-se nos textos alheios, nesta classe em que a linguagem escrita é aprendida na experiência de ler e de escrever.

A estratégia (2) merece um tratamento separado por destacar de modo muito explícito a entrada do Outro no texto das crianças. Essa estratégia caracteriza-se pela apresentação nas "intenções de texto" das crianças de palavras ou expressões legitimadas nos textos de pessoas autorizadas no espaço social, legitimando os próprios textos infantis, como pode ser visto no texto de Fernanda abaixo:

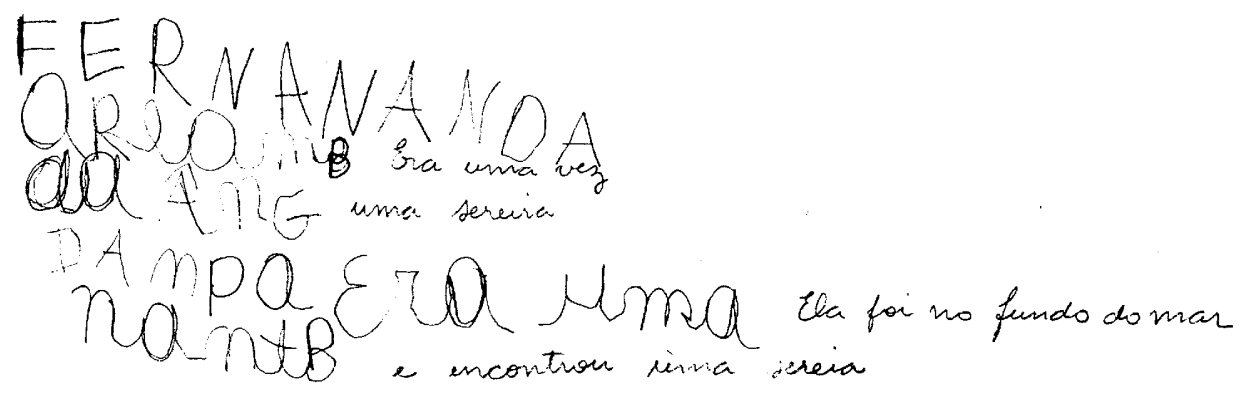

Leitura da criança:

Era uma vez

uma sereia.

Ela foi no fundo do mar.

E encontrou uma sereia. 


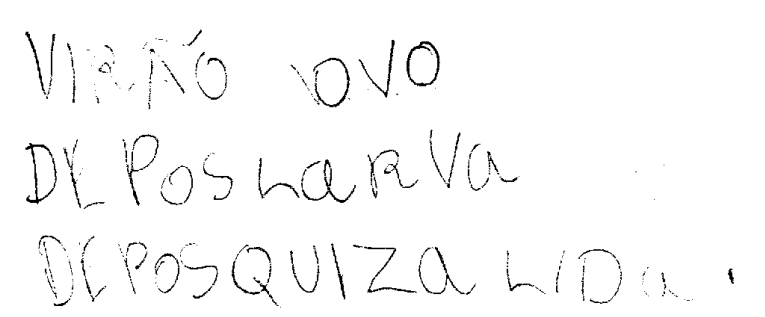

Camila

Lado esquerdo do texto:

Viram ovo,

Depois larva,

Depois crisálida.

BORBOLETAS E MARIPOSAS

BORBOLETAS

AS BORBOLETAS ELASTEN 4 ASAS ELA NACEN

A ASAS DAS BORBOLETAS NACEN COM ESCAMAS

AS BORBOLETAS TEN CABESATORCS E ABIDOME

AS BORBOLETAS TEN ANTENAS

SIVOCE TOCAR NA LACARTA QUEIMA

MARIPOSAS

AS MARIPOSAS DEN CORESCURAS

AS MARIPOSAS TEM ANTENAS

AS MARIPOSAS TANBENTEN CABESA TORACS E ABEDOME tha as Bobohtifs

pegan uma semete.

as PoBOhE ThS gho em

sparaE Do colopo
cabeca Tobax

ABrome ory bio-

RTO NOJO PODE . NOCS

o was Nas hagatas

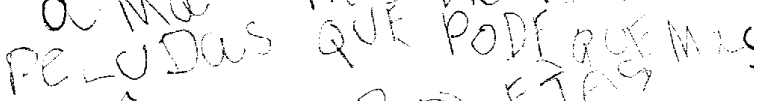

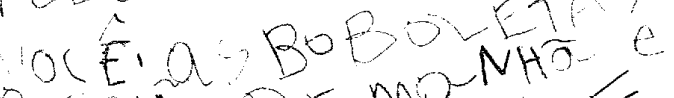

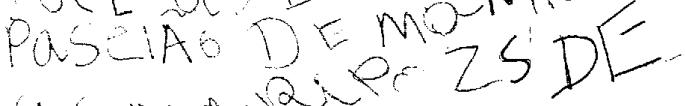

and 2

NOT?

Lado direito do texto:

Ela as borboletas

pegam uma semente.

As borboletas elas têm

3 partes do corpo:

Cabeça, tórax,

abdômen. As borbo-

letas não (se) pode colocar

a mão nas lagartas

peludas que pode queimar

você. As borboletas passeiam de manhã e

as mariposas de

noite. 
Fernanda insere na terceira linha de sua intenção de texto a escrita convencional "Era uma". Ressignifica desse modo no seu texto uma parcela de linguagem escrita do Outro, legitimando-o.

Outro ponto a destacar com relação aos processos estudados é que não foram encontrados textos orais escritos. Em muitos estudos sobre alfabetização, apresentam-se de modo tácito textos escritos por crianças que, na verdade, são textos escritos em linguagem oral. Esta característica encontra-se até de uma certa forma naturalizada na literatura, como se isso fosse esperado, necessário como uma etapa do processo. De acordo com os resultados de minha pesquisa, esta é uma característica circunstancial, relacionada a aspectos da metodologia de alfabetização trabalhada. Por que esta característica não foi encontrada nos processos das crianças aqui estudadas? A explicação plausível é que o fato de elas terem acesso desde o início a materiais escritos legitimados socialmente, ouvindo leituras, discutindo-as e, aos poucos, lendo e escrevendo. Os textos de Camila e de Vítor, abaixo, que podemos considerar um relatório de observação e estudo da transformação de lagartas em borboletas e mariposas, mostram o esforço das crianças para produzirem um texto em linguagem escrita.

A observação dos dois textos aponta para o destaque das crianças a aspectos dos objetos em questão que lhes parecem mais significativos. Chama atenção no segundo texto, de Vítor, a organização temática do texto em duas partes distintas: Borboletas e Mariposas, sendo que também lhe dá este título geral. Já Camila, no primeiro texto, parece estar lidando com mais dificuldades para garantir a organização sintático-discursiva de seu texto. As crianças são apresentadas desde o início à língua escrita como um sistema complexo, altamente convencional e dissociado da língua oral. Isso parece favorecer uma distinção mais rápida entre as duas modalidades de linguagem verbal.

A atividade de reflexão sobre o que está sendo produzido enquanto escrevem também parece indiciar a presença do Outro materializado no que se repete na língua, isto é, nas convenções sociais. Esta atividade manifesta-se nas soluções diferenciadas que as crian- ças dão para os mesmos problemas, de um modo geral ortográficos, em um mesmo texto. Por outro lado, a oscilação apresentada no nível sintático-discursivo pode estar relacionada tanto à repetição, na direção da estabilização dos sentidos das palavras e expressões, quanto às múltiplas possibilidades de "dizer" num texto. O fragmento de texto de Fabiana, abaixo, ilustra essa segunda possibilidade e mostra a tensão entre recursos expressivos, a forma ativa (furaram as casas) e a forma passiva (todas as casas foram furadas), na terceira linha, para a apresentação da informação.

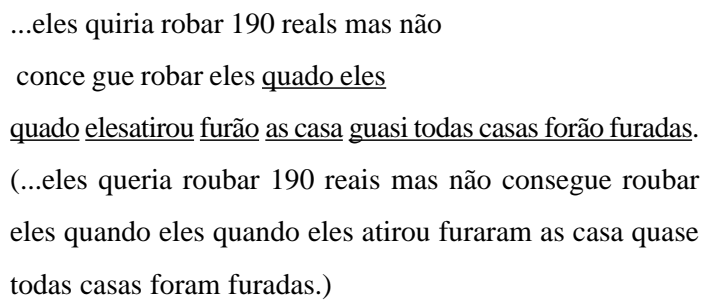

Outro destaque nesse texto, que também nos encaminha para o Outro do discurso, é a escrita da palavra reais como reals. Observa-se que Fabiana está operando com as categorias da língua escrita; no caso usando a desinência "s", característica da flexão de número. Como diz Abaurre (1988, p.140), a afirmação de que a criança escreve como fala é ingênua e equivocada, já que as crianças recorrem à oralidade para fazer hipóteses sobre a escrita, mas também usam a escrita para analisar a própria fala, como acontece na ocorrência em questão.

A mesma professora da turma e as mesmas propostas de produção, muitas vezes em função de um mesmo texto, são capazes de levar os alunos, que são diferentes, porque têm histórias de vida diferentes, participam de grupos sociais diferentes, interagindo portanto com o Outro de forma diferente, a textos marcadamente diferentes. Os textos seguintes, de Gabriel, Marcos Vinicius e Raphael, respectivamente, anunciam as condições polifônicas de suas construções, apontando para indícios de diferentes estilos de linguagem. O título da notícia foi escrito no quadro de giz pela professora. Esta é uma prática sua, sempre que está trabalhando com textos: apresentar os títulos, os autores, conversar sobre os temas envolvidos, bus- 


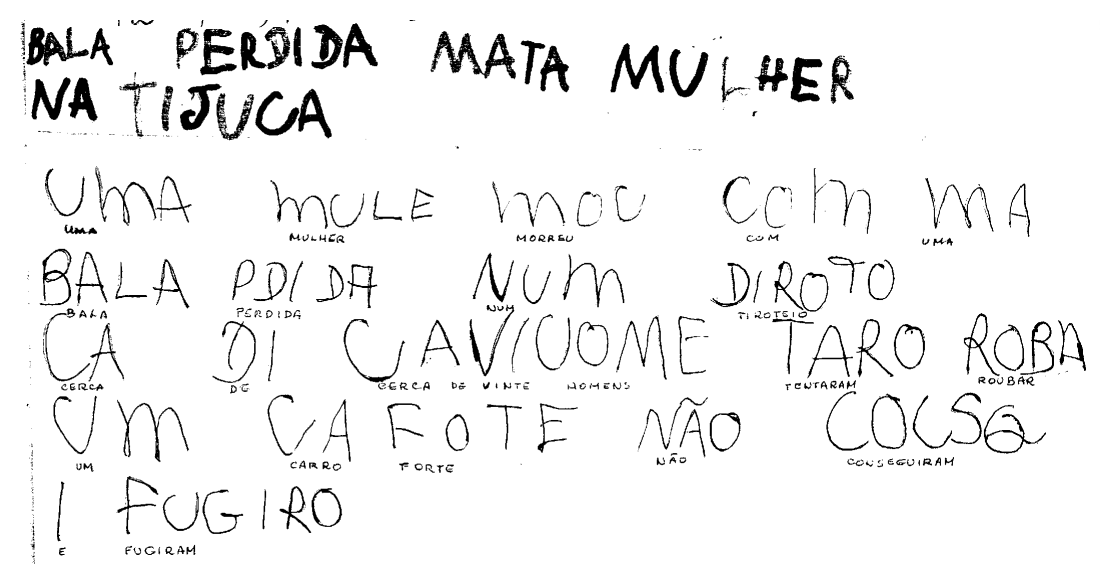

Leitura da criança:

Uma mulher morreu com uma

bala perdida num tiroteio.

Cerca de cerca de vinte homens tentaram roubar

um carro forte. Não conseguiram

e fugiram.

\section{BALA PERDIDA MATA MULHER NA TIJUCA}

\section{CAI20 IOEUIAC AOTI TAURE OARAM IOACUTRIDET}

CARSERHOMSIASLANANMTBS NIALTOGLFECOSRAREF

\section{U CA U CAIAU MITS UMHANIA}

\section{Leitura da criança:}

Cerca de 20 homens, assaltantes, tentaram roubar dinheiro de um carro forte.

Uma bala perdida matou uma mulher num tiroteio.

Os ladrões conseguiram fugir.

Um cara do carro forte ligou para a polícia.

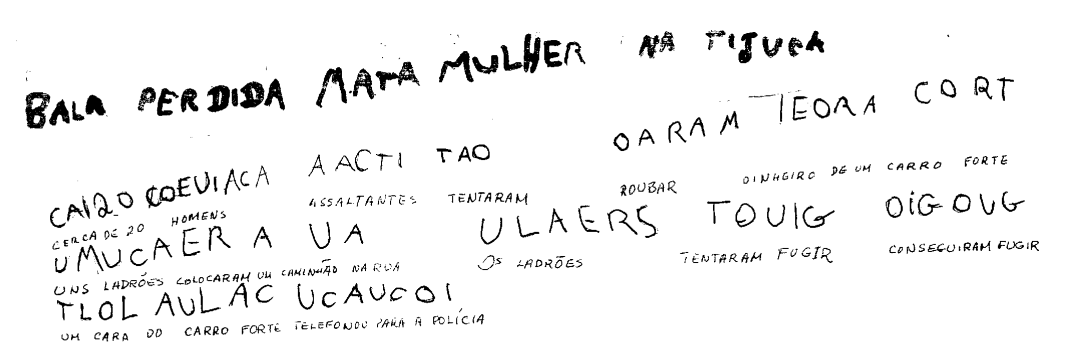

Leitura da criança:

Cerca de 20 homens assaltantes tentaram roubar dinheiro de um carro forte.

Uns ladrões colocaram um caminhão na rua.

Os ladrões tentaram fugir; conseguiram fugir.

Um cara do carro forte telefonou para a polícia. 
cando provocar as crianças para relacionar os temas e os autores a outros textos conhecidos ou lidos, e a situações da vida dos alunos - desse modo a interdiscursividade vai sendo construída, cruzando os gêneros discursivos da vida cotidiana com outros gêneros de discurso.

É interessante observar como a escrita da professora se introduz nos textos das crianças, marcando a presença simultânea da orientação convencional da escrita e das orientações possíveis às crianças nesse momento.

No segundo texto é possível observar as marcas da oralidade atravessando a escrita, de modo mais acentuado nos finais das formas verbais "tentaram" e "fugiram", expressas como "taro" e "fugiro", em que o ditongo nasal final é reduzido. Um sentido polifônico pode ser depreendido nesta particularidade também.

A estratégia (9) indicia que algumas crianças ficam muito absortas com a construção do objeto textual, no interior de convicções muito próprias sobre a operacionalização do sistema de escrita. Este pareceu ser o caso das crianças que durante um período usaram seus próprios nomes como referência, como alfabeto básico, para suas produções escritas. A análise do processo de Raphael, de modo mais explícito, permitiu observar que à medida que ele começou a considerar o material escrito a sua volta como fonte para a escrita de seus textos, houve um sensível salto de qualidade. No texto abaixo, escrito logo no início do ano letivo, o menino faz uma pequena alteração no seu nome, ao escrever a parte da história d'Os Três Porquinhos, e lê como: "Eu gostei mais do pedaço que o lobo mau assoprou a casa".

\section{Considerações Finais}

A noção de letramento pode ser encarada, diante do que foi exposto, como um horizonte ético-político para a escola. Formar pessoas letradas no sentido de abrir as possibilidades de entrada de outras vozes em suas vidas, histórias e discursos, outros modos de conhecer, ver e viver no mundo, do interior de uma perspectiva crítica. Essas outras vozes estariam em per- manente tensão, compondo as orientações de letramento dos sujeitos, como espectros fragmentários de conhecimentos, coesamente organizados e parcialmente partilhados dependendo das interações de que se participa.

O papel da escola seria, como foi dito na introdução, não só o de ampliar os conhecimentos de os alunos, mas o de ampliar as possibilidades de os alunos continuarem a aprender. Esta ação parece estar ligada à vida cotidiana das crianças que, interligada a outros universos conceituais, lhes possibilitaria estabelecer pontes, fazer relações e gerar novas interpretações dos diversos aspectos da realidade.

Pelo que pode ser observado na releitura dos resultados da pesquisa de 1997, as crianças vão agenciando recursos para a construção da linguagem interagindo com os Outros do discurso. As crianças vão apreendendo o valor simbólico da linguagem em questão, e ao mesmo tempo apropriando-se dela como uma nova forma de linguagem. As discussões sobre os usos sociais da linguagem escrita através de textos, temas e situações variadas, bem como autores variados são estruturantes da produção pelas crianças de textos escritos, com valor social, fundando as suas identidades em linguagem escrita nas identidades sociais. Estas atividades infantis sugerem que as crianças vão ampliando a possibilidade de desenvolver estratégias metadiscursivas, interligando complexamente os conhecimentos relacionados às várias áreas do conhecimento. Nesse sentido, é necessário repensar a forma como vêm sendo selecionados os conteúdos curriculares. O trabalho definido com base em eixos temáticos pode mostrar-se relevante, já que os textos orais e escritos, que são produzidos e/ou circulam no espaço da sala de aula, são sempre polifônicos, e envolvem conceitos de áreas diversas.

Considerando que os conhecimentos são sempre produzidos e que essa produção é também determinada pelas diferentes visões de mundo dos sujeitos, condicionadas pela cultura das classes sociais e pelas singularidades destes sujeitos, o espaço social letrado constitui-se em arena para que, de modo crítico, dialoguem e lutem as múltiplas perspectivas de saber e de participação criadora de todos. 
Ao articularmos discursivamente as noções de polifonia e letramento, surgem novas possibilidades de investigação que vamos perseguindo e aprofundando para, cada vez mais, entendermos a complexidade do processo de alfabetização como uma área matriz para a compreensão do papel da escola e dos trabalhos político-pedagógicos nela realizados. Estes estudos podem contribuir como fermento para que a escola seja uma instituição de todos, em que todos tenham vez e voz, pessoas de todas as classes sociais, mas, especialmente, aquelas das classes populares que têm sido, sistematicamente, excluídas do processo social.

CECÍLIA MARIA ALDIGUERI GOULART é doutora em Letras pela PUC-Rio e professora adjunta da Faculdade de Educação da Universidade Federal Fluminense, atuando no Programa de Pós-Graduação em Educação. Publicações recentes: A apropriação da linguagem escrita e o trabalho alfabetizador na escola, $\mathrm{Ca}$ dernos de Pesquisa (São Paulo, Fundação Carlos Chagas n 110 , p. 157-175, jul. 2000) e Leveza, visibilidade, multiplicidade e consistência: as "competências" do professor, Presença Pedagógica (v. 6, n 36, nov.-dez. 2000). E-mail: cecilia@ism.com.br

\section{Referências Bibliográficas}

ABAURRE, M. B. M., (1988). The interplay between spontaneous writing and underlying Linguistic representations. European Journal of Psychology of Education, v. 3, n $\mathrm{n}^{\circ}$, p. 415-430.

AZEVEDO, C. C. A., (2000). Leituras da mídia, leituras da escola: o "toque mágico" apaga ou transforma? Dissertação de Mestrado. Programa de Pós-Graduação em Educação, Universidade Federal Fluminense.

BAKHTIN, M. (V. N. Volochínov), (1988). Marxismo e filosofia da linguagem. São Paulo: Hucitec. (1992). Estética da criação verbal. São Paulo: Martins Fontes.

CASTRO, E. Ribeiro de, (1997). O irreversível e o áporo. In: BRAIT, B., (org.). Bakhtin, dialogismo e construção do sentido. Campinas: Editora da UNICAMP.

FOUCAULT, M., (1996). A ordem do discurso. São Paulo: Loyola.

GINZBURG, C., (1989). Mitos, emblemas e sinais - morfologia e história. São Paulo: Companhia das Letras, p. 143-179.
GNERRE, M., (1985) Linguagem, escrita e poder. São Paulo: Martins Fontes.

GOULART, C. M. A., (1999). Uma reflexão sobre a prática da alfabetização. Folha PROLER, 9, Fundação Biblioteca Nacional/Casa da Leitura, p. 7-8.

(2000a). Ensinar a ler e a escrever: novas perspectivas teórico-metodológicas. Movimento - Revista da Faculdade de Educação da Universidade Federal Fluminense, Rio de Janeiro, DP\&A Editora, p.145-154.

, (2000b). Uma abordagem bakhtiniana da noção de letramento. Trabalho apresentado no painel "Perspectivas Bakhtinianas para o Ensinar e Aprender". $10^{\circ}$ ENDIPE - Encontro Nacional de Didática e Prática de Ensino, UERJ.

(2000c). A produção de textos narrativos, descritivos e argumentativos: evidências do sujeito na/da linguagem. Trabalho apresentado na sessão coordenada: Argumentação e escrita, III Congresso de Psicologia do Desenvolvimento, Niterói, Universidade Federal Fluminense. , (2000d). A apropriação da linguagem escrita e o trabalho alfabetizador na escola. Cadernos de Pesquisa, São Paulo, Fundação Carlos Chagas, nº 106, p. 172-186.

HEATH, S. B., (1982). What no bedtime story means: narrative skills at home and school. Language in Society, II, p. 49-76.

KLEIMAN, A. B., (1995). Modelos de letramento e as práticas de alfabetização na escola. In: KLEIMAN, A. B., (org.). Os significados do letramento. Campinas: Mercado de Letras.

MACHADO, L. C. F., (1999). Interações discursivas e aprendizagem no contexto da sala de aula de Ciências. Dissertação de Mestrado. Programa de Pós-Graduação em Educação da Universidade Federal Fluminense.

MELLO, M. B. de, (1998). A multiplicidade das formas de ser racional: escrita e racionalidade. Dissertação de Mestrado. Programa de Pós-Graduação em Educação da Universidade Federal Fluminense.

MICHALOWSKI, P., (1994). Writing and literacy in early states: a mesopotamianist perspective. In: KELLER-COHEN, D., (ed.). Literacy - Interdisciplinary Conversations. Cresskill, NJ: Hampton Press, p. 49-70.

MORRISON, K., (1995). Estabelecendo o texto: a institucionalização do conhecimento por meio das formas históricas e filosófi- 
cas de argumentação. In: BOTTÉRO, J. et al. Cultura, pensamento e escrita. São Paulo: Ática, p. 141-200.

MORTIMER, E. e MACHADO, A. H., (1997). Múltiplos olhares sobre um episódio de ensino: "Por que o gelo flutua na água?" Anais do Encontro sobre Teoria e Pesquisa em Ensino de Ciências, Faculdade de Educação, Universidade Federal de Minas Gerais.

OLSON, D. R., (1977). From utterance to text: the bias of language in speech and writing. Harvard Educational Review, v. 47, p. $257-281$. , (1988). A escrita e a mente. In: WERTSCH, J. V. et al., (org.). Estudos socioculturais da mente. Porto Alegre: Artmed.

ORLANDI, E. P. (1988). Discurso e leitura. São Paulo: Cortez; Campinas: Editora da UNICAMP.

PACHECO, C. M. G., (1997). Era uma vez os sete cabritinhos: a gênese do processo de produção de textos escritos. Tese de Doutorado, Departamento de Letras da Pontifícia Universidade Católica do Rio de Janeiro.

RAMA, A., (1985). A cidade das letras. São Paulo: Brasiliense.

ROMMETVEIT, R., (1985). Language acquisition as increasing linguistic structuring of experience and symbolic behavior control. In: WERTSCH, J. V., (ed.). Culture, communication and cognition - Vygotskian Perspectives. Cambridge: Cambridge University Press.

SOARES, M. B., (1998). Letramento - um tema em três gêneros. Belo Horizonte: Autêntica.

SMOLKA, A. L. B., (1991). A prática discursiva na sala de aula: uma perspectiva teórica e um esboço de análise. Caderno CEDES, Campinas, $\mathrm{n}^{\circ} 24$, p. 51-65.

STOCK, B., (1993). The implications of literacy: written language and models of interpretation in the eleventh and twelfth centuries. Princeton, NJ: Princeton University Press.

STREET, B. V., (1984). Literacy in theory and practice. Cambridge: Cambridge University Press.

TEALE, W. H., (1992). Home background and young children's literacy development. In: TEALE, W. H., SULZBY, E., (ed.). Emergent literacy - writing and reading. Norwood, NJ: Ablex.

TERZI, S. B., (1997). A construção da leitura. Campinas: Pontes e Editora da UNICAMP.

TFOUNI, L. V., (1996). Letramento e alfabetização. São Paulo: Cortez. 


\section{Resumos/Abstracts}

\section{Cecília M. A. Goulart}

\section{Letramento e polifonia: um estudo} de aspectos discursivos do processo de alfabetização

O estudo busca aprofundar a compreensão da noção de letramento, discutindo novas bases teórico-metodológicas para a prática pedagógica alfabetizadora. Tal compreensão constitui-se colocando-se a noção de letramento em diálogo com a noção de polifonia, de Bakhtin, no contexto de sua teoria da enunciação. Os conceitos de interlocução e de gêneros discursivos têm também um papel relevante no estudo, interligados com posicionamentos teóricos de outros autores. A discussão realiza-se do interior da pesquisa que a autora vem desenvolvendo desde 1992, em uma escola pública do Rio de Janeiro, investigando os processos de apropriação do discurso escrito pelas crianças. Em textos de crianças de seis anos, destaca indícios da presença do(s) outro(s), revelando a dimensão alteritária dos processos de constituição da linguagem escrita. As crianças entrecruzam formas de dizer, vivenciando a tensão de sentidos existente no uso de diferentes estratégias e recursos expressivos e, ao mesmo tempo, revelando-se como sujeitos da/na linguagem. A noção de letramento é sugerida como um horizonte ético-político para a escola.
Literacy and polyphony: a study of different dimensions of discourse in the literacy process

This study seeks to expand the understanding of the notion of literacy by discussing new theoreticalmethodological bases for the pedagogical practice of literacy. This understanding is based on Bakhtin's notion of literacy in dialogue with that of polyphony in the context of his theory of enunciation. The concepts of interlocution and of types of discourse also have a relevant role in the study interwoven with theoretical postures of other authors. The discussion evolves from research in which the author has been engaged since 1992 in a state school in the city of Rio de Janeiro, investigating the processes by which children appropriate the written discourse. The article highlights the signs of the presence of the 'other' in texts written by six-year-old children, which reveal the dimension of alterity in the process of constituting written language. The children mix forms of expression as a means of experimenting the tension of senses existing in the use of different strategies and expressive resources and, at the same time, revealing themselves as subjects of and in language. The notion of literacy is posited as an ethical-political horizon for the school.
Sandra Llosa; María Teresa Sirvent; Amanda Toubes e Hilda Santos

\section{La situación de la educación de} jóvenes y adultos en la Argentina Presenta el diseño y los avances de la investigación "Estructura de poder, participación y educación: Estudio de la situación de la Educación de Jóvenes y Adultos en un contexto de neoconservadurismo, políticas de ajuste y pobreza" (Dir.: Sirvent). Esta investigación tiene como objeto de análisis: la demanda y la oferta por educación de jóvenes y adultos en regiones seleccionadas de Argentina. El estudio se desarrolla a través de la articulación de tres equipos de investigación regionales. Se busca obtener una descripción e interpretación de la demanda y elaborar lineamientos de políticas educativas y recomendaciones pedagógicas. El abordaje metodológico es combinado: cuantitativo - cualitativo con instancias participativas. El proceso de investigación desarrollado ha permitido centrar nuestra preocupación en la posibilidad de reproducción o de ruptura de: a) la situación de profunda pobreza educativa (Nivel de Riesgo Educativo) en que se halla el $75 \%$ de la población de 15 años y más que asistió pero no asiste más a la escuela en nuestro país y b) del principio de avance acumulativo en educación (re- 